\title{
Complexation of rare earth metals by quercetin and quercetin-5' -sulfonic acid in acidic aqueous solution
}

\author{
Maxim A. Lutoshkin a,b,*, Alexander I. Petrov ${ }^{\mathrm{a}, \mathrm{c}}$, Alexandr S. Kazachenko ${ }^{\mathrm{a}}$, \\ Boris N. Kuznetsov ${ }^{\mathrm{a}, \mathrm{c}}$ and Vladimir A. Levdansky ${ }^{\mathrm{a}}$ \\ anstitute of Chemistry and Chemical Technology SB RAS, Federal Research Center "Krasnoyarsk \\ Science Center SB RAS”, Krasnoyarsk, Russian Federation \\ ${ }^{\mathrm{b}}$ Université de Lyon, Université Claude Bernard Lyon 1, CNRS, UMR 5256, IRCELYON, Institut de \\ recherches sur la catalyse et l'environnement de Lyon, Villeurbanne, France \\ ${ }^{\mathrm{c}}$ Institute of Non-Ferrous Metals and Materials Science, Siberian Federal University, Krasnoyarsk, \\ Russian Federation
}

\begin{abstract}
The aqueous complexation of some lanthanides(III) and lanthanum(III) ions with quercetin and quercetinsulfanate are reported. The equilibrium stability constants for the formation of 1:1 monocomplexes Ln(III)-quercetin/ quercetinsulfanate (Ln(III)=La(III), Ce(III), Pr(III), Nd(III), Sm(III), Eu(III), Gd(III), Tb(III), Dy(III), Er(III), Tm(III), $\mathrm{Yb}(\mathrm{III})$ ) were determine in an acetic buffered solution. The measurements were conducted by spectrophotometric method at $293 \mathrm{~K}$ and $I=1\left(\mathrm{NaClO}_{4}\right)$. Structures of formed complexes were suggested with using DFT simulations.
\end{abstract}

Keyword: Quercetin, quercetinsulfanate, O-donor ligands, lanthanides

\section{Introduction}

The $3,5,7,3^{\prime}, 4^{\prime}$-pentahydroxyflavone or quercetin is the typical representative of plant-derived flavonoids - a large family of natural polyphenolic compounds widely distributed in nature [1]. The numerous fruits, flowers and vegetables contain flavonoids, including quercetin [2]; they contain it not only in its free form, but also in the form of glycosides [3]. Like other flavonoids quercetin possess wide spectrum of biological properties such as antioxidant [4], antiviral [5], anticancer [6], immunosuppressive [7] and other [8] features. In addition, quercetin exhibit pronounced cardiovascular protecting activity $[9,10]$. Due to the presence of all these properties quercetin found diverse application in medicine and pharmacology [11]. Moreover, quercetin can effectively chelate metal ions [12]. In literature describe solid complexes of quercetin with alkali [13], transition [13, 14], rare earth [15] and noble $[16,17]$ metals. Research linked to study of aqueous complexation between quercetin and $\mathrm{La} \mathrm{[18],} \mathrm{Fe}$ [19], $\mathrm{Pb}$ [20] has been demonstrated difficult behavior of current ligand. Some of these complexes have antioxidative and anti-tumour activities [13]. How we can see, complexation of

\footnotetext{
*Corresponding author: Maxim A. Lutoshkin. E-mail: maximsfu@yahoo.com.
} 
metals by quercetin has already been reported, but information about $\mathrm{Ln}$ (III)-quercetin interactions in solution have not been satisfactorily elucidated. The aim of this study was to investigation and interpretation of equilibrium processes of formation monocomplexes species $\mathrm{Ln}$ (III) with quercetin (Qrc) and quercetinsulfanate (Qsn) in aqueous solution.

\section{Experimental details}

\subsection{Reagents}

The UV-Vis spectra were measured with the Leki SS2109-UV scanning spectrophotometer (Leki Instruments, Finland) using $1 \mathrm{~cm}$ quartz cells. Cell thermostating $( \pm 0.1 \mathrm{~K})$ was performed with the Haake K15 thermostat connected to the Haake DC10 controller. The absorbance of process solutions was measured within $220-450 \mathrm{~nm}$. All measurements were performed at $298 \mathrm{~K}$.

All chemicals were of analytical grade: quercetin (Aldrich $\geq 95 \%, \mathrm{HPLC}$ ), $\mathrm{CH}_{3} \mathrm{COONa}, \mathrm{CH}_{3} \mathrm{COOH}$, $\mathrm{H}_{2} \mathrm{SO}_{4}, \mathrm{NaClO}_{4}, \mathrm{LnCl}_{3} \cdot 6 \mathrm{H}_{2} \mathrm{O}, \mathrm{Ln}=\mathrm{La}, \mathrm{Ce}, \mathrm{Pr}, \mathrm{Nd}, \mathrm{Sm}, \mathrm{Eu}, \mathrm{Gd}, \mathrm{Tb}, \mathrm{Dy}, \mathrm{Er}, \mathrm{Tm}, \mathrm{Yb}$. All stock solutions were obtained by dissolution of dry salts and ligand weights. The metal salts and ligands were dissolved in distilled water. The concentration of ethanol did not exceed $2 \%$ in the final solution. Buffer solutions within the $\mathrm{pH}$ range from 4.60 to 5.60 were prepared with $\mathrm{CH}_{3} \mathrm{COOH}$ and $\mathrm{CH}_{3} \mathrm{COONa}$. The accurate desired $\mathrm{pH}$ values were obtained by adjusting the molarities of the buffer components in suitable amounts. The complex formation process have been investigated spectrophotometrically.

\subsection{Ab initio study}

Calculations were performed using the GAMESS [21] program package with the Super-computer of the Institute of Space and Information Technologies (SFU). Geometry optimization was performed by density functional theory (DFT) with the functional PBE0 [22] under Grimme's empirical correction [23]. The Def2-SVP [24] basis set was applied for C, O, H, S and La(III) atoms. The solvent effects were evaluated using the SMD solvation model [25]. The optimized geometries were visualized with the ChemCraft software.

\subsection{Uv-vis measurements}

Conditional stability constants $\left(K^{\prime}\right)$ for monocomplex species were calculated from the equations $1-2[26]$ :

$$
\begin{gathered}
A_{\text {calc }}^{\lambda}=\varepsilon_{L}^{\lambda}\left(C_{L}-[M L]\right)+\varepsilon_{M}^{\lambda}\left(C_{M}-[M L]\right)+\varepsilon_{M L}^{\lambda}[M L], \\
{[M L]=1 / 2\left[\left(1 / K^{\prime}+C_{L}+C_{M}\right)+\sqrt{\left(1 / K^{\prime}+C_{L}+C_{M}\right)-4 C_{M} C_{L}}\right],}
\end{gathered}
$$

where $A_{c a l c}^{\lambda}$ is an absorbance at a given wavelength, $C_{M}$ and $C_{L}$ were analytical concentrations of $\operatorname{Ln}\left(\right.$ III) and ligand, respectively. The $\varepsilon^{\lambda}$ is a value of molar extinction coefficient at single wavelength. The optimal values for $\mathrm{K}^{\prime}$ and $\varepsilon^{\lambda}$ were found from the least squares analysis [27]:

$$
f\left(C_{M}, C_{L}, K^{\prime}, \varepsilon_{i}\right)=\sum_{i=1}^{n}\left(A_{i}^{\lambda}-A_{i}^{c a l c}\right)^{2} \stackrel{K^{\prime}, \varepsilon_{i}}{\longrightarrow} \min .
$$

Calculations of all equilibrium constants and molar extinction coefficients were performed using Scilab 5.5 software [28]. 


\subsection{Synthesis of quercetin-5'-sulfonic acid}

The pure quercetin is poorly soluble in water. For effective complexation and extraction of lanthanides on practice, we need ligand with more high solubility. Therefore, our group has been investigated the complexation with soluble derivatives of quercetin. The simplest water-soluble derivative of quercetin is the quercetin-5'-sulfonic acid. The synthesis of sulfonate derivatives of quercetin was described in research [29]. At this work was used similar simple method: $10 \mathrm{ml}$ of concentrated sulphuric acid was added $2.5 \mathrm{~g}$ of quercetin in $25 \mathrm{ml}$ round-bottom flask, the solution was vigorously stirred for $2 \mathrm{~h}$ at $80^{\circ} \mathrm{C}$ (Scheme 1).

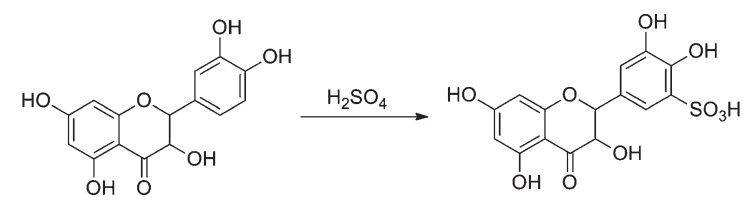

Scheme 1. Reaction scheme of synthesis of quercetinsulfanate.

The obtained orange product was separated by centrifugation and recrystallized from water; yield $75 \%$.

\section{Results and discussion}

\subsection{Uv-vis study}

As flavonoids are colored compounds, complexation process causes changes in color and in the electronic absorption spectra of the solution. The Qrc/Qsn-Ln(III) systems were study under the conditions of an excess amount of metal and a constant concentration of ligand. For all systems the buffer region was 4.60-5.60. All raw spectroscopic data are given in the Supplementary Material (Tables S1-S24).

Figure 1 shows typical spectra of quercetin at different concentration of Cerium(III). Figure S1 demonstrated that $\Delta \mathrm{A}$ maximum remains invariant at 420 at different cerium concentration one might conclude that complex formation leads to the only product (monocomplex species) with rather negligible contribution from the polynuclear species $\mathrm{Ce}_{n} \mathrm{~L}_{\mathrm{m}}$. A similar reasoning is applied to each of studied system. The following equations [30]:

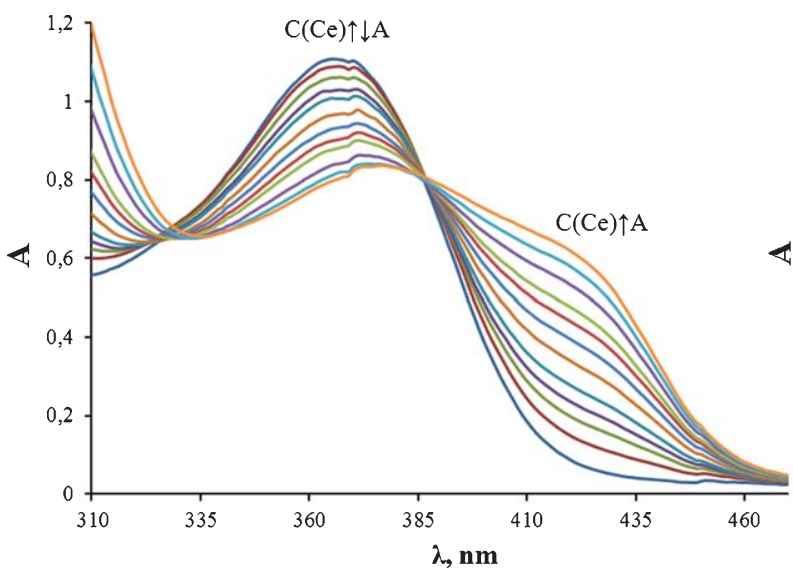

Fig. 1. The UV-Vis spectra and absorbance at single $\mathrm{C}($ Quercetin $)=5.29 \cdot 10^{-4} \mathrm{M} ; \mathrm{pH}=5.0, \mathrm{I}=1\left(\mathrm{NaClO}_{4}\right)$.

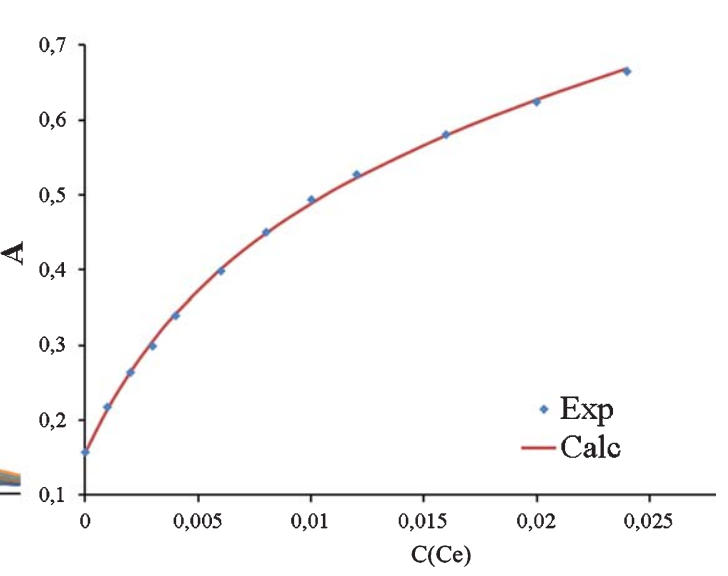
wavelength $(412 \mathrm{~nm})$ for $\mathrm{Ce}(\mathrm{III})-$ Quercetin system; 


$$
\begin{aligned}
& K=\alpha_{M} \alpha_{L} K^{\prime}, \\
& \alpha_{M}=1+\sum \beta_{n}[L]^{n}, \\
& \alpha_{L}=1+\sum K^{H}\left[H^{+}\right],
\end{aligned}
$$

were fitted for calculation "true" $(K)$ equilibrium stability constant. In equations $4-6 K_{H}$ is $1 / K_{a}, K$ and $\beta_{\mathrm{n}}$ is the conditional and cumulative stability constants, respectively. For evaluation of coefficients $\alpha_{M}$ and $\alpha_{L}$ value of $p K_{a}$ of ligands [31], stability constants of acetic and hydroxo complexes [32-39] of lanthanides have been used. All data used for calculation $\alpha_{M}$ and $\alpha_{L}$ demonstrated in Table S25.

The obtained values of equilibrium constants and extinctions are given in Tables 1 and 2. Although $\Delta \mathrm{A}$ maximum for Qrc-Ln(III) spectra lie near $420 \mathrm{~nm}$, all parameters for this systems were reproduce at $412 \mathrm{~nm}$ for the convenience of calculation at this wavelength. For receiving of more information about structures of complexes, some of systems has been study under various $\mathrm{pH}$ values. The results imply the linear correlation between $\log K^{\prime}$ and acidity of solution. This indicates that only one proton has been removed during the complexing process.

As can be seen the obtained values of "true" equilibrium constants lie within from 5 to 9 logarithmic units. The strongest and weakest interaction has been observed for $\mathrm{Yb}^{\mathrm{III}}$ and $\mathrm{Ce}^{\mathrm{III}} / \mathrm{La}^{\mathrm{III}}$ complexes, respectively. Quercetin and quercetinsulfanate formed comparably strong complexes with Tm(III), $\mathrm{Er}(\mathrm{III}), \mathrm{Tb}(\mathrm{III})$ and $\mathrm{Dy}(\mathrm{III})$. The stabilities of the quercetin chelates with different lanthanides ions are somewhat lower than those of Qsn. Regarding all of other metal complexes of quercetin, current rare earth metals format more stable species. All of investigated complexes are much stable than monocomplexes Qrc with $\mathrm{Ca}^{2+}, \mathrm{Mg}^{2+}, \mathrm{Co}^{2+}$ and $\mathrm{Ni}^{2+}$ [12].

According to [12] $\log \mathrm{K}$ for $\mathrm{La}^{\mathrm{III}}$-quercetin monocomplex in water/dioxan $(1: 1, \mathrm{v} / \mathrm{v})$ media is 8.143 vs. $5.77 \mathrm{log}$ units for our value. The difference in results more than 2 logarithmic units can be explain by numerous difference of solvent effects in water and in water/dioxane mixture.

The "true" stability constants of monocomplex species decrease in the order: $\mathrm{Yb}>\mathrm{Tm}>\mathrm{Er}>$ $\mathrm{Tb}>\mathrm{Dy}>\mathrm{Eu}>\mathrm{Pr}>\mathrm{Sm}>\mathrm{La}>\mathrm{Nd}>\mathrm{Gd}>\mathrm{Ce}$ and $\mathrm{Tb}>\mathrm{Dy}>\mathrm{Tm}>\mathrm{Er}>\mathrm{Gd}>\mathrm{Tb}>\mathrm{Pr}>\mathrm{Sm}>\mathrm{Eu}>\mathrm{Nd}>\mathrm{Ce}>\mathrm{La}$ for Qrc

Table 1

Conditional $\left(K^{\prime}\right)$, "true" $(K)$ stability constants and value of extinction for Qrc-Ln ${ }^{\mathrm{III}}$

\begin{tabular}{lcccc}
\hline $\mathrm{Ln}(\mathrm{III})$ & $\mathrm{pH}$ & $\log K^{\prime} \pm 0.02$ & $\log \varepsilon^{412} \pm 0.03$ & $\log { }^{2} \pm 0.05$ \\
\hline $\mathrm{La}$ & 5.60 & 2.61 & 3.11 & $5.77 ; 8.143[1]$ \\
$\mathrm{Ce}$ & 5.60 & 2.67 & 3.11 & 5.41 \\
& 5.20 & 2.28 & 3.11 & 5.38 \\
& 5.00 & 2.10 & 3.09 & 5.39 \\
$\mathrm{Pr}$ & 5.00 & 1.99 & 3.25 & 5.95 \\
$\mathrm{Nd}$ & 5.20 & 2.21 & 3.23 & 5.59 \\
$\mathrm{Sm}$ & 5.00 & 2.05 & 3.32 & 5.81 \\
$\mathrm{Eu}$ & & 2.43 & 3.28 & 6.12 \\
$\mathrm{Gd}$ & 5.20 & 2.07 & 3.38 & 5.49 \\
$\mathrm{~Tb}$ & & 2.67 & 3.26 & 6.43 \\
$\mathrm{Dy}$ & 5.60 & 3.05 & 3.26 & 6.40 \\
& 5.20 & 2.62 & 3.29 & 6.36 \\
$\mathrm{Er}$ & 4.80 & 2.27 & 3.25 & 6.41 \\
$\mathrm{Tm}$ & 5.00 & 2.67 & 3.29 & 6.57 \\
$\mathrm{Yb}$ & & 2.74 & 3.37 & 6.65 \\
\hline
\end{tabular}


Table 2

Conditional $\left(K^{\prime}\right)$, "true" $(K)$ stability constants and value of extinction for Qsn- $\mathrm{Ln}^{\mathrm{III}}$

\begin{tabular}{lcccc}
\hline $\mathrm{Ln}(\mathrm{III})$ & $\mathrm{pH}$ & $\log K^{\prime} \pm 0.02$ & $\log \varepsilon^{420} \pm 0.03$ & $\log K \pm 0.05$ \\
\hline $\mathrm{La}$ & 5.40 & 2.74 & 4.28 & 5.90 \\
$\mathrm{Ce}$ & 4.60 & 2.44 & 4.27 & 6.12 \\
& 5.00 & 2.73 & 4.25 & 6.02 \\
& 5.40 & 3.27 & 4.27 & 6.19 \\
$\mathrm{Pr}$ & 5.00 & 2.83 & 4.24 & 6.79 \\
$\mathrm{Nd}$ & & 3.09 & 4.26 & 6.66 \\
$\mathrm{Sm}$ & & 3.02 & 4.25 & 6.78 \\
$\mathrm{Eu}$ & & 3.00 & 4.26 & 6.70 \\
$\mathrm{Gd}$ & & 3.56 & 4.28 & 7.17 \\
$\mathrm{~Tb}$ & 4.60 & 2.80 & 4.22 & 7.16 \\
& 5.00 & 3.22 & 4.23 & 7.15 \\
& 5.40 & 3.58 & 4.25 & 7.12 \\
$\mathrm{Dy}$ & 5.40 & 3.56 & 4.27 & 7.50 \\
$\mathrm{Er}$ & 5.00 & 3.50 & 4.26 & 7.40 \\
$\mathrm{Tm}$ & & 3.56 & 4.27 & 7.47 \\
$\mathrm{Yb}$ & & 3.81 & 4.24 & 8.60 \\
\hline
\end{tabular}

Table 3

The orders of stability constants of monocomplexes for different ligands with Ln(III)

\begin{tabular}{lcc}
\hline Ligand & Coordination & Series \\
\hline Quercetin & $\mathrm{O}$ & $\mathrm{Yb}>\mathrm{Tm}>\mathrm{Er}>\mathrm{Tb}>\mathrm{Dy}>\mathrm{Eu}>\mathrm{Pr}>\mathrm{Sm}>\mathrm{La}>\mathrm{Nd}>\mathrm{Gd}>\mathrm{Ce}$ \\
Quercetin-5-sulfanate & & $\mathrm{Tb}>\mathrm{Dy}>\mathrm{Tm}>\mathrm{Er}>\mathrm{Gd}>\mathrm{Tb}>\operatorname{Pr} \sim \mathrm{Sm}>\mathrm{Eu}>\mathrm{Nd}>\mathrm{Ce}>\mathrm{La}$ \\
Ethylenediaminetetraacetate [40] & $\mathrm{O}, \mathrm{N}$ & $\mathrm{Yb}>\mathrm{Tm}>\mathrm{Er}>\mathrm{Dy}>\mathrm{Tb}>\mathrm{Gd}>\mathrm{Eu}>\mathrm{Sm}>\mathrm{Nd}>\operatorname{Pr}>\mathrm{Ce}>\mathrm{La}$ \\
Diethylenetriamine pentaacetate [40] & & $\mathrm{Tm}>\mathrm{Dy}>\mathrm{Er}>\mathrm{Yb}>\mathrm{Tb}>\mathrm{Eu}>\mathrm{Gd}>\mathrm{Sm}>\mathrm{Nd}>\operatorname{Pr}>\mathrm{Ce}>\mathrm{La}$ \\
Barbituric acid [41] & $\mathrm{O}$ & $\mathrm{Tm} \sim \mathrm{Yb}>\mathrm{Er}>\mathrm{Eu}>\mathrm{Dy}>\mathrm{Sm}>\mathrm{Nd}>\mathrm{Pr}>\mathrm{Tb}>\mathrm{Gd}>\mathrm{Ce}>\mathrm{La}$ \\
Carbonate ion [42] & $\mathrm{O}$ & $\mathrm{Yb}>\mathrm{Tm}>\mathrm{Er}>\mathrm{Dy}>\mathrm{b}>\mathrm{Gd}>\mathrm{Eu}>\mathrm{Sm}>\mathrm{Nd}>\mathrm{Pr}>\mathrm{Ce}>\mathrm{La}$
\end{tabular}

and Qsn, respectively. Table 3 given as an example the various ratios of stability constants for some heterocyclic ligands and lanthanides. We may notice that the obtained orders of stability constants are typical for heterocyclic ligand. The LogK-Ln(III) and $\log$ K-Z/R relationship curve are shown at Fig. 2. The pronounced correlation for $\log \mathrm{K}-\mathrm{Z} / \mathrm{R}$ is not observe, but all lanthanides separated by two groups: $\mathrm{La}-\mathrm{Eu}$ (Z/R from 2.5 to 2.8) and Gd-Yb (Z/R from 3.0 to 3.3). Moreover, Gd-Yb group displayed the weak linear correlation of $\log \mathrm{K}-\mathrm{Z} / \mathrm{R}$ relationship. This fact indicate that the electrostatic interaction higher for $\mathrm{Gd}-\mathrm{Yb}$ group than for La-Eu group of metals.

\subsection{The DFT calculations}

For verification of chosen coordination model $a b$ initio calculations at level Def2SVP/DFT/PBE0/SMD were performed. All theoretical simulations were implemented for $\mathrm{La}(\mathrm{III})$-complexes. This choice stems from the fact that $\mathrm{La}$ is the eponym of the lanthanide series and all theoretical results obtained for $\mathrm{La}(\mathrm{III})$ also can be extrapolated for all of other lanthanides. In addition, calculation of other lanthanides with using different modern quantum chemical programs and computational protocols are difficult problem for large systems like Ln-Qsn/Qrc complexes. No 

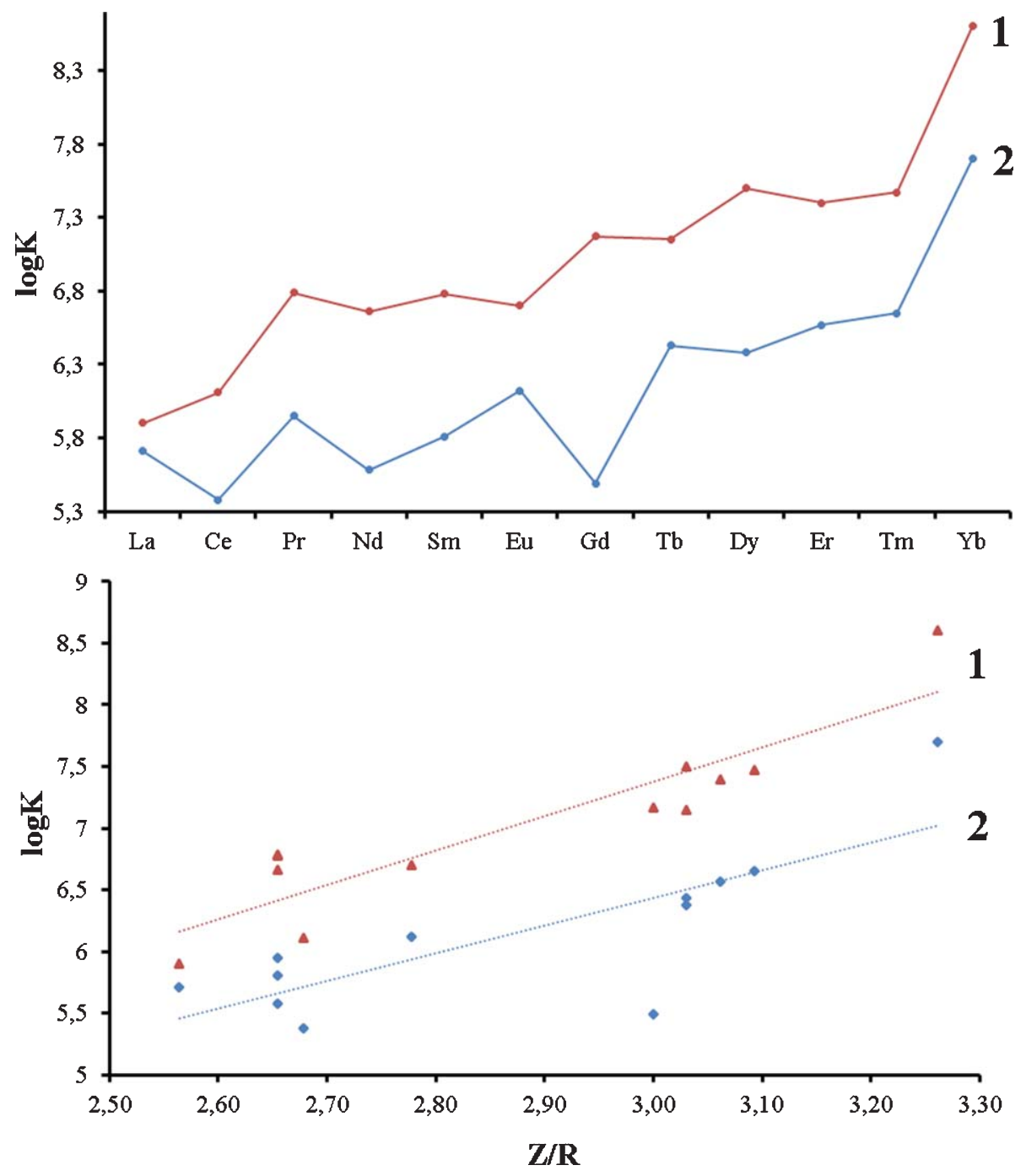

Fig. 2. The $\log \mathrm{K}-\mathrm{Ln}(\mathrm{III})$ and $\log \mathrm{K}-\mathrm{Z} / \mathrm{R}$ curves for quercetinsulfanate(1) and quercetin(2).

modern existing theoretical approaches allow obtain optimized structure for Qsn/Qrc complexes with metals from $\mathrm{Ce}$ to $\mathrm{Yb}$.

According to [12] quercetin have three possible chelating sites and one linear structure. La(III)Quercetinsulfanate may exist as seven tautomers. They are collected in Figure S2 and S3. All calculations of optimization structures were carried out on the model $\mathrm{La}\left(\mathrm{H}_{2} \mathrm{O}\right)_{6} \mathrm{~L}^{2+}$. For estimation of thermodynamic stable of tautomers absolute and relative energy for each of structures were calculated (Table S26 and S27). It was found that the 3-hydroxyl and 4-carbonyl chelating site (Fig. 3) is the most stable structure for La ${ }^{\mathrm{III}}$-Qsn/Qsa monocomplexes. All other tautomers are of much greater energy (more than $20 \mathrm{~kJ} \cdot \mathrm{mol}^{-1}$ ).

\section{Conclusion}

Within this study, the equilibrium processes between La(III) and 11 lanthanides with quercetin and quercetinsulfanate have been investigated in aqueous solution. The obtained complexes species has 

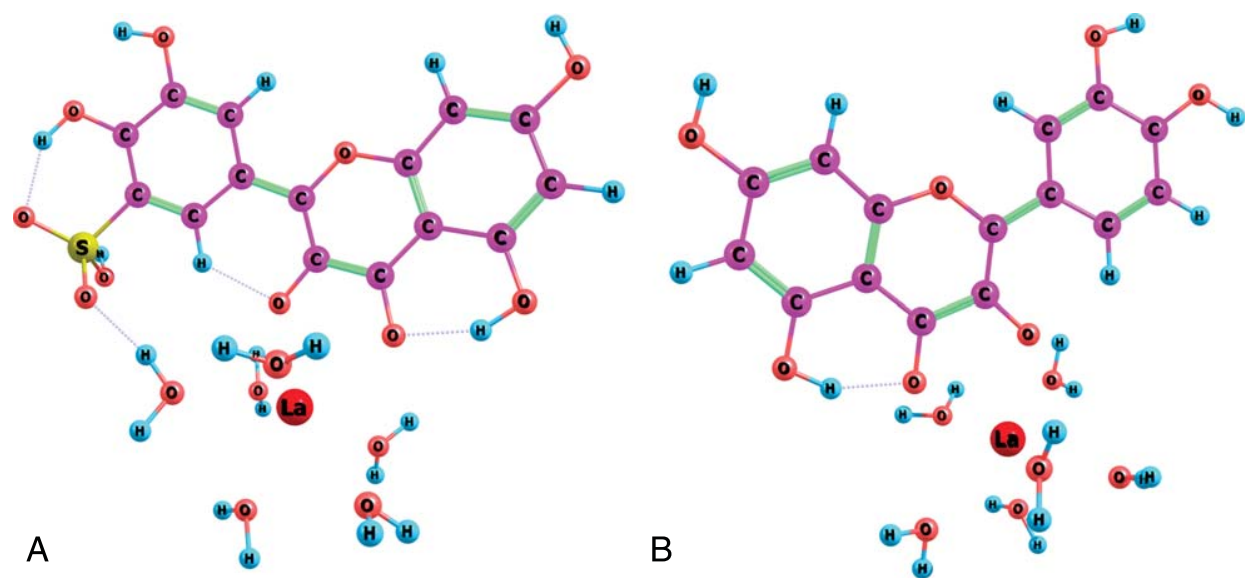

Fig. 3. Optimization geometry of $\mathrm{La}(\mathrm{III})-\mathrm{Q} n(\mathrm{~A})$ and $\mathrm{La}(\mathrm{III})-\mathrm{Qrc}(\mathrm{B})$ complexes.

the monocomplex structure with $\log \mathrm{K}$ from 5.4 to 8.6 logarithmic units. The DFT calculation shown that the $\mathrm{Ln}^{\mathrm{III}}$ coordinate with molecule of ligands via 3-hydroxyl and 4-carbonyl groups.

\section{Supplementary material}

The supplementary material is available in the electronic version of this article: http://dx.doi.org/ 10.3233/MGC-253.

\section{Acknowledgments}

The research has been funded by state contract (No 16-43-242083) of Russian Foundation for Basic Research and Government of Krasnoyarsk Region.

\section{References}

[1] L. Zhang, E. Angst, J.L. Park, A. Moro, D.W. Dawson, H.A. Reber, G. Eibl, O.J. Hines and V.L. Go, Quercetin aglycone is bioavailable in murine pancreas and pancreatic xenografts, J Agric Food Chem 58 (2010), 7252-7257.

[2] I. Trendafilova, A. Szegedi, J. Mihály, G. Momekov and N.M. Lihareva, Preparation of efficient quercetin delivery system on Zn-modified mesoporous SBA-15 silica carrier, Materials Science and Engineering: C 73 (2017), $285-292$.

[3] S.G. Dmitrienko, V.A. Kudrinskaya and V.V. Apyari, Methods of extraction, preconcentration, and determination of quercetin, Journal of Analytical Chemistry 67 (2012), 299-311.

[4] A.T. Jan, M.R. Kamli, I. Murtaza, J.B. Singh and A. Ali, Dietary flavonoid quercetin and associated health benefits-an overview, Food Rev Int 26 (2010), 302-317.

[5] E. Moretti, L. Mazzi, G. Terzuoli, C. Bonechi, F. Iacoponi, S. Martini, C. Rossi and G. Collodel, Effect of quercetin, rutin, naringenin and epicatechin on lipid peroxidation induced in human sperm, Reprod Toxicol 34 (2012), 651-657.

[6] G.L. Russo, M. Russo, C. Spagnuolo, I. Tedesco, S. Bilotto, R. Iannitti and R. Palumbo, Quercetin: A pleiotropic kinase inhibitor against cancer, Cancer Treat Res 159 (2014), 185-205.

[7] N. Haleagraharaa, S. Miranda-Hernandez, A. Alima, L. Hayesa, G. Birdc and N. Ketheesana, Therapeutic effect of quercetin in collagen-induced arthritis, Biomedicine \& Pharmacotherapy 90 (2017), 38-34.

[8] R. Garcia-Mateos, L. Aguilar-Santelises, M. Soto-Hernandez and R. Nieto-Angel, Flavonoids and antioxidant activity of flowers of Mexican Crataegus spp, Nat Prod Res 27 (2013), 834-836.

[9] L. Xiao, L. Liu, X. Guo and S. Zhang, Quercetin attenuates high fat diet-induced atherosclerosis in apolipoprotein E knockout mice: A critical role of NADPH oxidase, Food and Chemical Toxicology 105 (2017), 22-33. 
[10] M. Pfeuffer, A. Auinger, U. Bley, I. Kraus-Stojanowic, C. Laue, P. Winkler, C.E. Rüfer, J. Frank, C. Bösch-Saadatmandi, G. Rimbach and J. Schrezenmeir, Nutr Metab Cardiovasc Dis 23 (2013), 403-409.

[11] G. D’Andrea, Quercetin: A flavonol with multifaceted therapeutic applications? Fitoterapia 106 (2015), $256-271$.

[12] M.M. Kasprzak, A. Erxleben and J. Ochocki, Properties and applications of flavonoid metal complexes, RSC Adv 5 (2015), 45853-45877.

[13] M. Kalinowska, G. Świderski, M. Matejczyk and W. Lewandowski, Spectroscopic, thermogravimetric and biological studies of $\mathrm{Na}(\mathrm{I}), \mathrm{Ni}(\mathrm{II})$ and $\mathrm{Zn}(\mathrm{II})$ complexes of quercetin, J Therm Anal Calorim 126 (2016), 141-148.

[14] J. Zhou, L. Wang, J. Wang and N. Tang, Antioxidative and anti-tumour activities of solid quercetin metal(II) complexes, Transition Metal Chemistry 26 (2001), 57-63.

[15] A. Ansari, 1H NMR, spectroscopic and molecular modeling studies on paramagnetic lanthanide(III)-quercetin complexes, Main Group Chemistry 8 (2008), 15-30.

[16] V. Kuntic, S. Blagojevic, D. MalesÏev, Z. Radovic and M. Bogavac, Spectrophotometric Investigation of the Pd(II)Quercetin Complex in 50\% Ethanol, Monatshefte fur Chemie 129 (1998), 41-48.

[17] J. Stawinska, M. Cieslak-Golonka, Z. Staszak and R. Gancarz, The reactivity of cis-platin. Spectroscopic properties of products isolated from the [cis- $\mathrm{Pt}\left(\mathrm{NH}_{3}\right)_{2} \mathrm{Cl}_{2}$-quercetin] and [cis- $\mathrm{Pt}\left(\mathrm{NH}_{3}\right)_{2} \mathrm{Cl}_{2}-\mathrm{CrVI}$-quercetin] systems, Transition Metal Chemistry 26 (2001), 153-159.

[18] V.G. Ferrari, N.B. Pappano, N.B. Debattista and M.P. Montan, Potentiometric and spectrophotometric study of 3hydroxyflavone-La(III) complexes, J Chem Eng Data 53 (2008), 1241-1245.

[19] J.M. Dimitric, Z.S. Markovic, T.P. Markovic and V.M. Brdaric, Iron complexes of dietary flavonoids: Combined spectroscopic and mechanistic study of their free radical scavenging activity, Food Chem 129 (2011), 1567-1577.

[20] J.P. Cornard, L. Dangleterre and C. Lapouge, Computational and spectroscopic characterization of the molecular and electronic structure of the $\mathrm{Pb}(\mathrm{II})$-quercetin complex, J Phys Chem A 109 (2005), 10044-10051.

[21] M.W. Schmidt et al., General atomic and molecular electronic structure system, S ComputChem 14 (1993), $1347-1363$.

[22] C. Adamo and V. Barone, Toward reliable density functional methods without adjustable parameters: The PBE0 model, J Chem Phys 110 (1999), 6158-6170.

[23] S. Grimme, J. Antony, S. Ehrlich and H. Krieg, A consistent and accurate ab initio parametrization of density functional dispersion correction (DFT-D) for the 94 elements H-Pu, J Chem Phys 132 (2010), 154104-154122.

[24] F. Weigend and R. Ahlrichs, Balanced basis sets of split valence, triple zeta valence and quadruple zeta valence quality for H to Rn: Design and assessment of accuracy, Phys Chem Chem Phys 7 (2005), 3297-3305.

[25] A.V. Marenich, C.J. Cramer and D.G. Truhlar, Universal salvation model based on solute electron density and on a continuum model of the solvent defined by the bulk dielectric constant and atomic surface tensions, $J$ Phys Chem $B$ 113 (2009), 6378-6396.

[26] S.A. Grebenyuk, I.F. Perepichka and A.F. Popov, Evaluation of the parameters of 1:1 charge transfer complexes from spectrophotometric data by non-linear numerical method, Spectrochim Acta Part A 58 (2002), 2913-2923.

[27] D.J. Leggett, Computational Methods for the Determination of Formation Constants, Plenum Press: New-York; 1985, pp. 478-480.

[28] http://www.scilab.org/

[29] M. Kopacz, Quercetin- and Morinsulfonates as Analytical Reagents, Journal of Analytical Chemistry 58 (2003), 225-229.

[30] A.I. Petrov, M.A. Lutoshkin and I.V. Taydakov, Aqueous complexation of Y(III), La(III), Nd(III), Sm(III), Eu(III), and Yb(III) with some heterocyclic substituted $\beta$-Diketones, Eur J Inorg Chem 6 (2015), 1074-1082.

[31] R. Alvarez-Diduk, M.T. Ramírez-Silva, A. Galano and A. Merkoçi, Deprotonation mechanism and acidity constants in aqueous solution of flavonols: A combined experimental and theoretical study, J Phys Chem B 117 (2013), 12347 12359.

[32] G.D. Klungness and R.H. Byrne, Comparative hydrolysis behavior of the rare earth and yttrium: The influence of temperature and ionic strength, Polyhedron 19 (2000), 99-107.

[33] R.S. Kolat and J.E. Powell, Acetate complexes of the rare earth and several transition metal ions, Inorg Chem 1 (1962), 293-296.

[34] B. Tagirova, A. Zotov, J. Schott, O. Suleimenov and L. Koroleva, A potentiometric study of the stability of aqueous yttrium-acetate complexes from 25 to $175^{\circ} \mathrm{C}$ and 1-1000 bar, Geochimica et Cosmochimica Acta 71 (2007), 16891708 .

[35] S. Deberdt, S. Castet, J.-L. Dandurand and J.-C. Harrichoury, Potentiometric study of Gd- and Yb-acetate complexing in the temperature range $25-808^{\circ} \mathrm{C}$, Chemical Geology 167 (2000), 75-88.

[36] C.F.F. Lopes, E.A. Neves, M. Encarnacion and V. Suarez-iha, potentiometric study of acetate complexes of lanthanum (III), Analytical Letters 27 (1994), 1749-1761. 
[37] F. Martínez and A. Gómez, Thermodynamic study of the solubility of some sulfonamides in octanol, water, and the mutually saturated solvents, J Solution Chem 30 (2001), 909-923.

[38] A. Sonesson, On the complex chemistry of the tervalent rare earth ions. I. the acetate systems of lanthanum, cerium, neodymium, and gadolinium, Acta Chemica Scandinavica 12 (1958), 165-181.

[39] A.V. Zotov, B.R. Tagirov, I.I. Diakonov and K.V. Ragnarsdottir, A potentiometric study of Eu ${ }^{3+}$ complexation with acetate ligand from 25 to $170^{\circ} \mathrm{C}$ at $\mathrm{P}_{\text {sat }}$, Geochimica et Cosmochimica Acta 66 (2002), 3599-3613.

[40] T.F. Gritmon, M.P. Goedken and G.R. Choppin, The complexation of lanthanides by aminocarboxylate ligands, $J$ inorg nucl Chem 39 (1977), 2021-2023.

[41] S. Tabassum, K.S. Siddiqi and N.H. Khan, Studies on barbituric acid complexes of lanthanide ions, Indian J Chem $\mathbf{2 6}$ (1987), 523.

[42] F.J. Millero, Stability constants for the formation of rare earth-inorganic complexes as a function of ionic strength, Geochimica et Cosmochimica Acta 56 (1992), 3123-3132. 